\title{
Caracterização diagnóstica dos serviços que atendem vítimas de acidentes e violências em cinco capitais brasileiras
}

\author{
Diagnostic characterization of services providing care to victims \\ of accidents and violence in five Brazilian state capitals
}

Suely Ferreira Deslandes ${ }^{1}$

Edinilsa Ramos de Souza 2

Maria Cecília de Souza Minayo ${ }^{3}$

Cláudia Regina B. Sampaio Fernandes da Costa 4

Márcia Krempel 5

Maria de Lourdes Cavalcanti ${ }^{6}$

Maria Luiza Carvalho de Lima 7

Samuel Jorge Moysés 8

Maria Lúcia Leal 9

Cleber Nascimento do Carmo ${ }^{10}$

\begin{abstract}
${ }^{1}$ Departamento de Ensino, Instituto Fernandes Figueira, Fiocruz.

Av. Rui Barbosa, 716-, Flamengo, 22250-020, Rio de Janeiro RJ.

desland@iff.fiocruz.br

2 Claves, Departamento de Epidemiologia e Métodos Quantitativos em Saúde, ENSP, Fiocruz.

${ }^{3}$ Claves, ENSP, Fiocruz.

${ }^{4}$ Departamento de

Psicologia, Faculdade de

Educação, Ufam.

${ }^{5}$ Secretaria Municipal de Saúde, Prefeitura Municipal de Curitiba.

${ }^{6}$ Núcleo de Estudos de by 103 services: 34 from Recife, 25 from Rio de Janeiro, 18 from Manaus, 18 from Curitiba and 8 from Brasília. The still preliminary results indicate: lower number of services focusing on the elderly; scarce investment in preventive actions; the principal actions carried out are social assistance, ambulatory and hospital care and psychological assistance; patients received from Basic Health Units require attention of the communities and families; need for investment in capacity building programs for professionals; precarious registries, data handled manually. The wording of the National Policy for Reduction of Morbidity and Mortality from Accidents and Violence is not well-known and there is a lack of articulation among and inside sectors and between prehospital and emergency care services. Rehabilitation services are insufficient in all cities.
\end{abstract} Saúde Coletiva, UFRJ.

${ }^{7}$ Departamento de Medicina Social, UFPE.

${ }^{8}$ Centro de Ciências Biológicas e da Saúde, PUCPR.

${ }^{9}$ Departamento de Serviço Social, UnB.

${ }^{10}$ Claves, Fiocruz.
Abstract This article characterizes the services providing care to victims in five Brazilian regions with high violence and accident rates. It analyzes care activities and strategies, the profile of the teams, the conditions of installations, equipment and supplies, integrated care and registration services and the opinion of health managers with respect to the needs and requirements for a better care to the victims. The sample is composed

Key words Violence, Accidents, Public policies, Services
Resumo Este artigo caracteriza serviços que atendem as vitimas em capitais das cinco regiões brasileiras com altos indices de violências e acidentes. Analisamse atividades e estratégias de atendimento, perfil das equipes, condições das instalações, equipamentos e insumos, serviços integrados de atenção e de registro de agravos e a ótica de gestores de saúde sobre demandas e necessidades para uma atenção de qualidade às vítimas. O acervo se constitui de 103 serviços: 34 de Recife, 25 do Rio de Janeiro, 18 de Manaus, 18 de Curitiba e 8 de Brasília. Os resultados ainda preliminares indicam: menor número de serviços com atendimentos voltados a idosos; pouco investimento em ações de prevenção; suporte social, atendimento ambulatorial, hospitalar e psicológico são as principais ações empreendidas; encaminhamentos das unidades básicas de saúde requerem atenção nas comunidades e famílias; necessidade de investimentos na capacitação dos profissionais para atendimento; registros precários e feitos manualmente. $O$ texto da Política Nacional de Redução de Morbimortalidade por Acidentes e Violências épouco conhecidoe há desarticulação inter e intra-institucional e entre atendimento pré-hospitalar e de emergência. Em todas as cidades há insuficiência de serviços de reabilitação. Palavras-chave Violência, Acidentes, Políticas públicas, Serviços 


\section{Introdução}

A violência e os acidentes constituíam em 2005 a segunda causa de mortalidade geral no país e a sexta maior causa de internação hospitalar ${ }^{1}$. A demanda crescente de serviços para atendimento das lesões e traumas provocados por esses fenômenos requer novas habilidades, equipamentos e organização do sistema de saúde. Esses desafios exigem amplas reflexões, decisões e ações. O Ministério da Saúde, buscando oferecer diretrizes para a atuação dos estados e municípios, elaborou a "Política Nacional de Redução da Morbimortalidade por Acidentes e Violências"2.

As principais diretrizes dessa Política são: 1) promoção e adoção de comportamentos e de ambientes saudáveis; 2) monitorização da ocorrência de acidentes e de violências; 3 ) sistematização, ampliação e consolidação do atendimento pré-hospitalar; 4) assistência interdisciplinar e intersetorial às vítimas de acidentes e violências; 5) estruturação e consolidação do atendimento voltado à recuperação e à reabilitação; 6) capacitação de recursos humanos; 7) apoio ao desenvolvimento de estudos e pesquisas.

A Política introduz, oficialmente, o tema na agenda do setor saúde, ampliando o foco de sua abordagem antes restrita aos foros policiais e judiciários. Contudo, apesar da importância da promulgação de uma política específica para efetivar a atenção às violências e aos acidentes como um problema prioritário, a organização do sistema para acolher essa agenda tem sido lenta, fragmentada e constrangida pela demanda. Daí a importância de iniciativas avaliativas da implementação da Política, buscando apontar os avanços e as lacunas da atenção às vítimas e as formas de organização e investimento do setor para o monitoramento e enfrentamento desta situação.

O presente artigo constitui um estudo de parte dos dados da investigação "Análise diagnóstica de sistemas locais de saúde para atender aos agravos provocados por acidentes e violências". A pesquisa original objetiva realizar uma análise diagnóstica sobre a organização dos serviços de saúde voltados para atendimento aos agravos provocados por acidentes e violências em cinco capitais brasileiras (Rio de Janeiro, Recife, Brasília, Curitiba e Manaus), além de propor uma metodologia de avaliação para o atendimento às suas vítimas. Este artigo visa a caracterizar os serviços que atendem essas vítimas nas referidas capitais, analisando as atividades e estratégias de atendimento, o perfil das equipes, as condições das instalações, equipamentos e insumos, os serviços integrados na atenção e a forma de registro desses agravos. Analisa, ainda, a ótica dos gestores sobre as dificuldades para consolidar uma atenção de qualidade às vítimas.

O trabalho aborda a análise diagnóstica a partir de um olhar que integra o aprofundamento qualitativo e a magnitude quantitativa. Entendese por diagnóstico uma análise situacional que leva em conta, dentre outras dimensões, as condições gerais de infra-estrutura, de planejamento e de apoio oferecido visando ao êxito das ações. Esta pesquisa, de natureza estratégica, está comprometida com as respostas do sistema, buscando o aperfeiçoamento das ações a favor da população atendida ${ }^{3}$.

\section{Metodologia}

A investigação usa os princípios da triangulação de métodos, que considera: a) a combinação e o cruzamento de múltiplos pontos de vista; b) a tarefa conjunta de pesquisadores com formação diferenciada; c) a visão de diferentes informantes; e d) o emprego de uma variedade de técnicas de coleta de dados. Seu uso, na prática, permite interação, crítica intersubjetiva e comparação $0^{4-6}$.

A pesquisa original é interinstitucional e interdisciplinar. Fazem parte da equipe pesquisadores de vários programas de investigação e ensino das cinco cidades.

\section{Critérios de seleção das capitais}

O estudo inclui as cidades de Manaus, situada na região Norte, com população estimada para 2005 de 1.644.690 habitantes; Recife, com 1.501.008; Rio de Janeiro, com 6.094.183; Brasília, com 2.333.108; e Curitiba, com 1.757.904 habitantes ${ }^{7}$.

A escolha dessas cidades ocorreu a partir de estudo realizado por Souza et al. ${ }^{8}$ para o Ministério da Saúde, com o objetivo de subsidiar a implantação do Plano Nacional de Prevenção da Violência. O estudo incluiu 224 municípios do país com população acima de 100 mil habitantes, no qual foi construído um índice sintético de violência que usou o número de óbitos e as taxas de mortalidade por homicídio, acidente de transporte e suicídio, no ano de 2000. Todos os municípios foram ordenados a partir desse indicador sintético.

No ranking nacional as capitais aqui selecionadas situaram-se nas seguintes colocações: Rio de Janeiro, $2^{\circ}$ lugar; Recife, $3^{\circ}$; Brasília, 5०; Manaus, $13^{\circ}$; e, finalmente, Curitiba, no $17^{\circ}$ posto. Excetuando-se o Rio de Janeiro, todas as demais cidades foram as primeiras colocadas em suas respectivas 
regiões, sendo esse o critério definidor da sua escolha. No caso específico da região Sudeste, São Paulo foi a cidade com o mais elevado indicador de violência. Contudo, devido à complexidade dessa capital e visando à facilidade operacional do estudo, optou-se pela escolha da cidade do Rio de Janeiro, que ocupou o segundo posto em sua região.

Verifica-se nos dados mais recentes que todas as cidades continuavam apresentando, em 2003, taxas de homicídios acima da média nacional (28,2 por 100 mil habitantes): Brasília com 33,9; Curitiba com 28,5; Rio de Janeiro com 47,7; Recife com 67,4; e Manaus com 29,01.

\section{Instrumentos, coleta, processamento e análise dos dados}

Os instrumentos para a coleta de dados foram um questionário e um roteiro de entrevista semiestruturada. O questionário foi aplicado aos serviços que realizam atendimento de saúde às vítimas de acidentes e violências. Esse instrumento inclui 23 questões relativas às seguintes variáveis: tipo de instituição, população atendida, desenvolvimento de ações de prevenção, objetivos institucionais, atividades desenvolvidas, estratégias e meios empregados nas atividades, serviços envolvidos em encaminhamentos, número de atendimentos, tipo de registro, composição e capacitação da equipe para o atendimento, instalações físicas, equipamentos, insumos e origem dos recursos financeiros.

Dada a magnitude da rede de serviços de cada cidade, foram incluídos apenas os serviços que prestam atendimento específico e/ou diretamente voltado para as vítimas de violências/acidentes indicados por representantes das Secretarias Municipais e Estaduais de Saúde. Assim, foram excluídas as unidades que apenas eventualmente realizam essa atenção. Uma Unidade Básica de Saúde (UBS) só foi incluída, por exemplo, se fizesse algum trabalho focalizando a violência.

Pela mesma metodologia de consulta aos gestores da saúde foram identificadas as organizações nãogovernamentais (Ongs) que realizam atendimento às vítimas com clara interface de cuidados de saúde (excluíram-se aquelas que atendem somente na área da Segurança Pública ou Defesa de Direitos). O acervo se constitui de 103 serviços, sendo 34 de Recife, 25 do Rio de Janeiro, 18 de Manaus, 18 de Curitiba e 8 de Brasília. Desses serviços, 13 são Ongs, 2 são fundações e 88 são governamentais ligadas ao SUS (quatro delas conveniadas).

A pesquisa de campo nos serviços da Zona Oeste do Rio de Janeiro foi realizada, mas percalços de natureza operacional (a equipe foi vítima de assalto) impossibilitaram a apresentação desses resultados. Os dados estão sendo novamente coletados e serão incluídos em próximas publicações.

Os questionários foram digitados em um banco de dados (EpiData) e criticados. A análise teve um caráter exploratório, no qual foram usadas medidas estatísticas descritivas (freqüências simples e relativas) para todas as variáveis.

A entrevista foi aplicada aos gestores e especialistas envolvidos no planejamento, implantação e execução das ações de atendimento dos agravos causados por acidentes e violências (diretores de unidades, chefes de setores de emergência, responsáveis pelos serviços de resgate e coordenadores dos setores de epidemiologia e planejamento). Foram ouvidos profissionais e gestores ligados ao atendimento pré-hospitalar, à emergência e à reabilitação. Essas três áreas de atendimento são consideradas essenciais pela Política Nacional de Redução de Morbimortalidade por Acidentes e Violências. Os roteiros exploram a visão sobre as principais dificuldades encontradas nesses setores. Realizou-se um total de 23 entrevistas, sendo 5 de Curitiba, 6 de Brasília, 5 do Rio de Janeiro, 3 de Manaus e 4 de Recife.

As entrevistas foram transcritas e interpretadas segundo os princípios da análise de conteúdo, a partir de sua modalidade temática ${ }^{9}$. A análise de conteúdo foi conduzida por um recorte interpretativo ${ }^{10}$. Contudo, dado o caráter exploratório do estudo, os dados e informações relatados (conteúdos manifestos) foram priorizados. Foram percorridos os seguintes passos de análise: a) leitura flutuante de todo material; b) identificação e comparação das idéias e sentidos contidos em cada pergunta; c) descrição dos sentidos atribuídos pelos sujeitos nas respostas dos profissionais; d) esboço de hipóteses interpretativas.

\section{Resultados e discussão}

\section{Caracterização das instituições}

A maior presença no atendimento às vítimas de acidentes e violências é de serviços da rede pública municipal $(38,1 \%)$, seguida pelos da rede estadual $(37,1 \%)$, e apenas $7,2 \%$ federais. Os serviços conveniados com o SUS ou fundações/empresas constituem 5,8\% do acervo. Este dado reflete a organização do sistema público de saúde brasileiro, pois a execução das ações compete à esfera municipal. Contudo, o atendimento estadual é bem significativo. Além de financiar e formular políti- 
cas, caberia à esfera estadual coordenar sistemas regionais e realizar ações específicas de abrangência regional.

A rede estadual está mais representada em Brasília e Manaus, compreendendo, respectivamente, a totalidade dos serviços de Brasília e 66,7\% dos serviços computados em Manaus. Expressivo percentual dos serviços de Recife $(47,1 \%)$, metade dos de Curitiba e $48 \%$ dos situados no Rio de Janeiro são municipais. A rede pública federal é mais presente em Manaus, onde constitui 16,7\% das unidades estudadas.

Verifica-se modesta presença das Ongs em ações de atendimento da área da saúde para as vítimas de violências e acidentes (12,6\% da totalidade dos serviços). Elas estão mais presentes em Recife (20,6\% dos serviços), além de também constituírem 16\% dos serviços do Rio.

A predominância dos serviços públicos nesse conjunto faz com que $92,2 \%$ dos serviços estudados sejam formalmente institucionalizados, indicando potencial continuidade das ações. O grau de institucionalização é de $100 \%$ em Manaus e o menor percentual se observa em Brasília (75\%).

Considerando-se os 103 serviços, 34 estão localizados em Recife incluindo 14 serviços de préhospitalar, 7 hospitais, 6 de reabilitação e 7 Ongs. No Rio de Janeiro os 25 serviços estão distribuídos entre 8 de pré-hospitalar, 12 hospitais, 1 de reabilitação e 4 Ongs. Em Manaus, as 18 unidades incluem 8 hospitalares, 7 unidades de pré-hospitalar e 3 de reabilitação. Os 18 serviços de Curitiba se constituem de 7 unidades de pré-hospitalar, 6 hospitais, 3 de reabilitação e 2 Ongs. Brasília apresenta 8 serviços, sendo 4 hospitais e 4 pré-hospitalares. Alguns desses serviços caracterizados como pré-hospitalar dizem respeito a ambulatórios especializados no atendimento às vítimas. As Ongs constituem um grupo heterogêneo de iniciativas, desde aquelas voltadas para as vítimas de violência conjugal, dos maus-tratos de crianças e adolescentes e suas famílias, até aquelas de atendimento de reabilitação física.

Como mostra a tabela 1 , os grupos em situação de violência/acidentes considerados "grupos alvos de atendimento" - seja pelos critérios de faixa etária, gênero etc. - mais freqüentemente atendidos por esses serviços é o de crianças/adolescentes (92,2\%). Em seguida vem o grupo de mulheres, ao qual 79,6\% das unidades prestam atendimento. O grupo familiar, considerado uma unidade de atenção, é o que menos foi mencionado. Apenas 26,2\% desses serviços informaram prestar-lhe atendimento.

Entre as cidades, Curitiba e Manaus apresentam as maiores proporções de serviços que atendem aos homens, mulheres e idosos. Todos os serviços de Manaus e Brasília informaram que atendem crianças/adolescentes e são elevados os percentuais de serviços que atendem jovens nessas duas cidades $(88,9 \%$ em Manaus e $87,6 \%$ em Brasília).

A predominância do atendimento às crianças e adolescentes confirma que esta temática, sendo também a que mais congrega publicações, dentre todas as formas de violências e acidentes, tem demonstrado mais visibilidade e envolvimento da comunidade acadêmica no seu estudo e nas suas formas de intervenção ${ }^{11}$.

A expressiva participação das mulheres nos grupos de atendimento também revela os frutos da luta histórica do movimento feminista no Brasil, que consolida na saúde uma pauta de atuação. Os idosos despontam neste cenário da atenção às vítimas de acidentes e violências mais recentemente. Em contrapartida, os familiares são ainda pouco abordados como eixo de atenção, o que desconsidera a dinâmica de produção e reprodução da violência, que encontra nos múltiplos papéis e arranjos familiares o seu principal locus ${ }^{12}$.

\section{Tabela 1}

Proporções de serviços que prestam atendimento, segundo grupos.

\begin{tabular}{lcccccc}
\hline & $\begin{array}{c}\text { Criança/ } \\
\text { Adolescente }\end{array}$ & Jovens & Homens & Mulheres & Idosos & Familiares \\
\hline Brasília & 100 & 87,5 & 62,5 & 75,0 & 50,0 & 37,5 \\
Curitiba & 94,1 & 72,2 & 83,3 & 83,3 & 72,2 & 61,1 \\
Manaus & 100 & 88,9 & 88,9 & 88,9 & 77,8 & 11,1 \\
Recife & 85,3 & 58,8 & 55,9 & 76,5 & 52,9 & 11,8 \\
Rio de Janeiro & 92,0 & 68,0 & 64,0 & 76,0 & 68,0 & 28,0 \\
Total & 92,2 & 70,9 & $\mathbf{6 8 , 9}$ & $\mathbf{7 9 , 6}$ & $\mathbf{6 4 , 1}$ & 26,2 \\
\hline
\end{tabular}




\section{Caracterização das atividades de atendimento}

A tabela 2 mostra que a maioria dos atendimentos aos acidentes e violências ocorre no Rio, Recife e Manaus, talvez pela dimensão que a violência assume nessas cidades. Nos anos de 2003 e 2004, esses atendimentos representaram cerca de $12 \%$ do total de pessoas atendidas. Esse percentual é um pouco maior em Recife, no ano de 2003; e no Rio, em 2004. Contudo, tais dados merecem ser relativizados, visto que o registro em muitas unidades visitadas é precário e que alguns se baseiam em estimativas. Vale ressaltar que, em Brasília, o único serviço que respondeu à questão atende somente vítimas de violências. Assim, o total de atendidos é o mesmo do número de pessoas em situação de acidentes/violência.

Dados de 2005 mostram percentuais de internações por lesões e envenenamento da ordem de $6,9 \%$ para o Brasil, dos quais 10,2\% em Curitiba, 7,6\% em Brasília, 7,4\% no Rio de Janeiro, 6,8\% em Recife e 5,5\% em Manaus ${ }^{1}$. As informações para os serviços que integram a pesquisa, em 2003 e 2004, incluem também atendimentos que não são contabilizados por Autorizações de Internação Hospitalar (AIH). Revelam percentuais bem mais elevados, por serem referência e por incluir os atendimentos ambulatoriais e de emergência.

Além do atendimento imediato às vítimas, observou-se que $42,3 \%$ dos serviços informaram também realizar ações de prevenção. Esse percentual é de $64 \%$ no Rio de Janeiro, 41,2\% em Recife, 37,5\% em Brasília, 27,8\% em Manaus e 16,7\% em Curitiba.
Considerando-se as cinco cidades e todos os objetivos institucionais dos seus serviços, o atendimento médico foi o predominante $(33,5 \%)$. Vale pontuar que a atenção à saúde é mais do que a atenção médica, porém a atenção à saúde sem o componente médico com qualidade e resolutividade dificilmente será satisfatória.

Destaque deve ser dado a Recife, por apresentar acompanhamento jurídico como objetivo de 8,1\% de seus serviços. A pesquisa é objetivo explícito dos serviços apenas no Rio, onde 2,2\% deles informaram esta missão, além da capacitação de profissionais, que é objetivo de 4,4\% dos serviços dessa mesma cidade.

Os principais tipos de ações de atendimento observados para o conjunto dos serviços, conforme pode ser verificado na tabela 3 , são o suporte social (que inclui uma diversidade de ações, como orientação sobre direitos, colocação no mercado de trabalho e orientação familiar) com $62,8 \%$, o atendimento ambulatorial (53,9\%), o atendimento hospitalar $(52,4 \%)$ e o acompanhamento psicológico (oferecido por $48 \%$ das unidades). Mais de $40 \%$ dos serviços fazem palestras e distribuem material educativo.

Em contrapartida, ações importantes são desigualmente empreendidas nas cidades: o acompanhamento psicológico é menos oferecido no Rio e em Curitiba; o grupo de pais é uma estratégia de atuação rara em Manaus e no Rio; oficinas de prevenção à violência quase nunca ocorrem em Manaus; e a visita domiciliar é menos utilizada pelos serviços de Curitiba (estratégia priorizada pelas UBS).

Considerando-se as necessidades de interse-

\section{Tabela 2}

Distribuição do total de atendimentos e dos atendimentos a pessoas em situação de acidentes e violências realizados pelos serviços/programas em 2003 e 2004.

\begin{tabular}{|c|c|c|c|c|c|c|c|c|}
\hline \multirow[t]{3}{*}{ Cidades } & \multicolumn{4}{|c|}{ Total de pessoas atendidas no serviço } & \multicolumn{4}{|c|}{ Total de pessoas em situação de violência atendidas } \\
\hline & \multicolumn{2}{|c|}{2003} & \multicolumn{2}{|l|}{2004} & \multicolumn{2}{|c|}{2003} & \multicolumn{2}{|c|}{2004} \\
\hline & $\mathrm{n}$ & $\%^{1}$ & $\mathrm{n}$ & $\% 1$ & $\mathrm{n}$ & $\%^{2}$ & $\mathrm{n}$ & $\%^{2}$ \\
\hline Brasília & $12.499(\mathrm{~T}=1)$ & 0,3 & $13.089(\mathrm{~T}=3)$ & 0,3 & $12.499(\mathrm{~T}=1)$ & 100,0 & $13.087(\mathrm{~T}=3)$ & 100,0 \\
\hline Curitiba & $608.096(\mathrm{~T}=12)$ & 13,8 & $731.205(\mathrm{~T}=14)$ & 15,5 & $51.038(\mathrm{~T}=7)$ & 8,4 & $77.864(\mathrm{~T}=11)$ & 10,6 \\
\hline Manaus & $279.213(\mathrm{~T}=11)$ & 29,0 & $1.243 .460(\mathrm{~T}=13)$ & 26,4 & $127.198(\mathrm{~T}=10)$ & 9,9 & $120.134(\mathrm{~T}=11)$ & 9,7 \\
\hline Recife & $1.150 .993(\mathrm{~T}=24)$ & 26,1 & $1.512 .176(\mathrm{~T}=33)$ & 32,0 & $164.071(\mathrm{~T}=15)$ & 14,3 & $160.432(\mathrm{~T}=20)$ & 10,6 \\
\hline Rio de Janeiro & $1.353 .884(\mathrm{~T}=17)$ & 30,8 & $1.216 .156(\mathrm{~T}=16)$ & 25,8 & $146.829(\mathrm{~T}=16)$ & 10,8 & $230.408(\mathrm{~T}=16)$ & 18,9 \\
\hline Total & 4.404 .685 & 100,0 & 4.716 .086 & 100,0 & 501.635 & 11,4 & 601.925 & 12,8 \\
\hline
\end{tabular}

1 Percentual calculado em relação ao total de atendimentos nas cinco cidades.

2 Percentual calculado em relação ao total de atendimentos da cidade em cada ano.

$\mathrm{T}$ Total de instituições que responderam à questão. 
Tabela 3

Proporções de serviços segundo tipos de ações e meios de atendimento.

\begin{tabular}{|c|c|c|c|c|c|c|}
\hline Ações/meios de atendimento & Brasília & Curitiba & Manaus & Recife & Rio de Janeiro & Total \\
\hline Pré-hospitalar móvel/fixo & 75,0 & 35,3 & 38,9 & 11,8 & 16,0 & 26,5 \\
\hline Hospitalar & 75,0 & 55,6 & 72,2 & 35,3 & 52,0 & 52,4 \\
\hline Reabilitação física & 50,0 & 33,3 & 38,9 & 32,4 & 20,0 & 32,0 \\
\hline Ambulatorial & 75,0 & 61,1 & 64,7 & 38,2 & 56,0 & 53,9 \\
\hline Suporte social & 100,0 & 61,1 & 61,1 & 55,9 & $\ldots$ & 62,8 \\
\hline Visita domiciliar & 37,5 & 22,2 & 27,8 & 32,4 & 32,0 & 30,1 \\
\hline Acompanhamento psicológico & 62,5 & 38,9 & 50,0 & 58,8 & 33,3 & 48,0 \\
\hline Grupo de pais & 37,5 & 16,7 & 5,6 & 26,5 & 4,0 & 16,5 \\
\hline $\begin{array}{l}\text { Grupo de crianças/adolescentes/ } \\
\text { jovens/mulheres/idosos }\end{array}$ & 25,0 & 11,1 & 11,1 & 29,4 & 28,0 & 22,3 \\
\hline Grupo de sala de espera & - & 11,1 & 5,6 & - & 16,0 & 6,8 \\
\hline Oficinas de prevenção à violência & 37,5 & 22,2 & 5,6 & 20,6 & 24,0 & 20,4 \\
\hline Palestras & 25,0 & 33,3 & 38,9 & 50,0 & 52,0 & 43,7 \\
\hline Distribuição de material educativo & 37,5 & 50,0 & 33,3 & 38,2 & 52,0 & 42,7 \\
\hline Outras & 37,5 & 27,8 & 25,0 & 17,6 & 50,0 & 30,0 \\
\hline
\end{tabular}

torialidade e de articulação setorial que o atendimento às vítimas de violências e acidentes demanda e que são ratificadas nas diretrizes da Política Nacional, buscou-se identificar quais serviços estão presentes nesta eventual rede de referência e contra-referência. Entre todas as cidades, os maiores percentuais foram de encaminhamentos de pacientes para o Conselho Tutelar (CT) $(64,7 \%)$, hospital geral $(58,8 \%)$, ambulatório especializado (57,6\%) e para hospitais especializados (56,9\%). Essa preponderância de encaminhamentos aos CT é coerente com o expressivo percentual informado de atendimentos a crianças e adolescentes.

A maioria dos serviços de cada cidade estudada encaminha pacientes para ambulatório especializado, hospital geral, emergência hospitalar, hospital especializado, CT, Delegacia de Proteção à Criança e Adolescente (DPCA) e para programas de assistência social.

Recife apresenta baixos percentuais de encaminhamentos em relação às demais cidades, talvez por congregar muitos serviços de referência. Entretanto, poucos são os encaminhamentos para serviços de proteção dos direitos e delegacias, o que sugere a necessidade de melhor articulação do setor saúde com demais setores. O CT é o mais freqüente, com 45,5\% dos serviços de Recife sendo encaminhados para este órgão.

Nas cidades pesquisadas, a maioria dos serviços informou que recebe os pacientes das UBS (55,8 \%), de unidades do Programa Saúde da Família (PSF,
$55,4 \%$ ) e do CT (49,5\%), sugerindo positivamente que as unidades que trabalham com as comunidades e famílias estão sensíveis à identificação das situações de acidentes e violências, funcionando como "portas de entrada" do sistema.

Há uma desigual participação das escolas, com um elevado percentual de encaminhamentos para o setor saúde e baixa contra-referência da saúde para essas organizações sociais. Vale tal destaque, pois essas instituições têm papel estratégico, por conviverem cotidianamente com crianças, adolescentes e suas famílias. As delegacias de atendimento aos idosos também apresentam modesta participação na rede de atuação, provavelmente pelo fato de existirem poucas unidades policiais para esse fim.

\section{Caracterização da estrutura dos serviços/programas}

Como se pode ver na tabela 4 , as principais categorias de profissionais existentes na maioria dos serviços são as de médico, assistente social, psicólogo e enfermeiro, constituindo equipes multidisciplinares. Algumas outras categorias como nutricionista, farmacêutico/bioquímico e outros profissionais de nível superior se destacam em Manaus, provavelmente por ter considerável concentração de hospitais no acervo. Algumas informações desta tabela merecem ser comentadas. Uma delas é a existência de as- 


\section{Gráfico 1}

Proporções de serviços que encaminham e recebem pacientes em situação de acidentes/violências, referentes às cinco cidades ${ }^{\star}$ brasileiras analisadas.

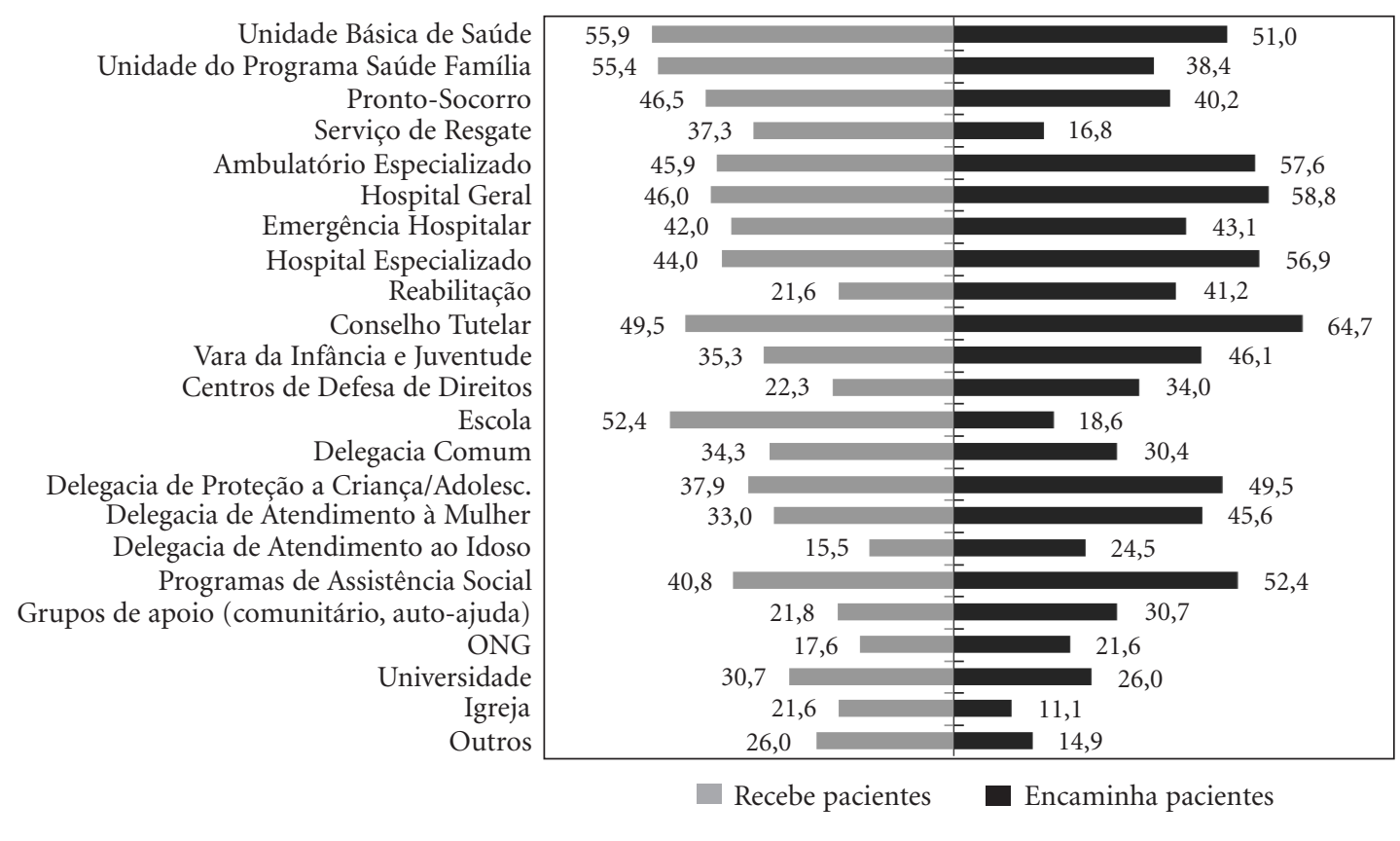

(*)Brasília, Curitiba, Manaus, Recife e Rio de Janeiro.

\section{Tabela 4}

Proporções de serviços, segundo categorias profissionais e ocupações.

\begin{tabular}{|c|c|c|c|c|c|}
\hline Categorias profissionais & Brasília & Curitiba & Manaus & Recife & Rio de Janeiro \\
\hline Médico & 100,0 & 88,9 & 88,9 & 64,7 & 87,5 \\
\hline Assistente social & 62,5 & 44,4 & 77,8 & 61,8 & 75,0 \\
\hline Psicólogo & 50,0 & 50,0 & 55,6 & 58,8 & 62,5 \\
\hline Enfermeiro & 37,5 & 66,7 & 77,8 & 41,2 & 62,5 \\
\hline Fisioterapeuta / fonoaudiólogo / terapeuta ocupacional & 12,5 & 33,3 & 33,3 & 26,5 & 12,5 \\
\hline Odontólogo & 12,5 & 38,9 & 27,8 & 23,5 & 16,7 \\
\hline Nutricionista & 37,5 & - & 75,0 & 11,8 & 25,0 \\
\hline Farmacêutico / bioquímico & 12,5 & 11,1 & 87,5 & - & 4,2 \\
\hline Professor / educador / pedagogo & 12,5 & 11,1 & 37,5 & 26,5 & - \\
\hline Profissionais de nível superior de outras áreas & - & 22,2 & 75,0 & 26,5 & 16,7 \\
\hline Auxiliar / Técnico de enfermagem & 75,0 & 72,2 & 33,3 & 20,6 & 50,0 \\
\hline Outros técnicos & 25,0 & 27,8 & 37,5 & 5,9 & 8,33 \\
\hline Estagiários (nível médio e superior) / graduandos & 37,5 & 33,3 & 25,0 & 5,9 & 16,7 \\
\hline Auxiliar de serviços gerais & 37,5 & 44,4 & 22,2 & 8,8 & 20,8 \\
\hline Auxiliar / agente administrativo & - & 44,4 & 25,0 & 2,9 & 8,3 \\
\hline Cozinheira / copeira & - & 5,6 & 12,5 & - & - \\
\hline Vigia/ guarda municipal / motorista / bombeiro & - & 38,9 & 50,0 & 2,9 & 4,2 \\
\hline
\end{tabular}


sistente social em somente $44,4 \%$ dos de $\mathrm{Cu}$ ritiba; e de enfermeiro em $37,5 \%$ das unidades de Brasília e 41,2\% das de Recife. Nesta última cidade, assim como em Manaus, também é baixo o percentual de serviços com auxiliar/técnico de enfermagem (20,6\% e 33,3\%, respectivamente).

Quanto à capacitação das equipes para atender a vítimas de acidentes e violências, $82 \%$ dos serviços das cidades informaram que realizam alguma atividade nesse sentido. Esse valor variou de $100 \%$ em Curitiba a 73,5\% em Recife, onde apresentou o menor percentual.

Para o conjunto das cidades, 32,6\% dos serviços informaram que tiveram capacitação há algum tempo. Esse período foi variável: $44,4 \%$ deles tiveram capacitação há 6 meses do período de realização da pesquisa; $11,1 \%$ haviam sido capacitados de 6 a 12 meses antes; $29,6 \%$ de 12 a 24 meses; e $14,8 \%$ foram capacitadas há mais de 24 meses.

Nas cidades, a capacitação é regularmente oferecida à equipe em 44,2\% dos serviços. Brasília destaca-se com o maior percentual de serviços (75\%), e chama atenção a cidade de Recife, onde esse valor é o mais baixo (24,0\%). Os serviços do Rio (57,9\%), Manaus (47,1\%) e Curitiba (41,2\%) se situam com valores intermediários em relação a essa questão.

A periodicidade da formação oferecida indica haver uma concentração maior em capacitações semestrais $(27,8 \%)$ e anuais $(22,2 \%)$, subentendendo-se que este investimento não é, de fato, continuado. Em 20,9\% dos serviços das cidades estudadas o profissional busca se capacitar por conta própria. Conforme esperado, essa busca é maior em Recife (40,0\%). Finalmente, 2,3\% dos serviços informaram que nenhuma capacitação é oferecida pelo serviço nem buscada pelo profissional. Nesse quadro mais grave, Manaus sobressai com 11,8\% dos seus serviços tendo feito tal afirmativa.

Os serviços avaliaram a suficiência e adequação da infra-estrutura de atendimento às vítimas de violência e acidentes. A maior precariedade apontada se refere à insuficiência das instalações físicas, de equipamentos, insumos e de equipe. No conjunto das cidades, Brasília e Rio se mostraram mais insatisfeitas comparando-se às demais.

No que se refere à avaliação da adequação desses quesitos, a situação se inverte, pois a maioria dos serviços de todas as cidades (exceto Brasília) informou que possui instalações adequadas.

A grande maioria dos serviços afirmou possuir registro dos dados, embora em 50\% deles estes sejam processados manualmente e apenas em $40 \%$ haja registro informatizado. Maior proporção de serviços com registro manual de dados foi observada em Brasília $(87,5)$ e maior per- centual de registro informatizado foi encontrado nos serviços de Manaus (64,7\%). Contudo, na fase de coleta nesta cidade se observou que as informações não estão, de fato, prontamente disponíveis. É importante ressaltar que, exceto em Brasília, ainda há muitos serviços que não fazem o registro das ações. Para o conjunto das cidades esse valor é de 10\%. Em Manaus e em Curitiba o montante é de $5,9 \%$ em cada uma dessas cidades. No Rio e em Recife ele atinge $12,5 \%$ e 14,7\% dos serviços, respectivamente.

Questionados sobre a realização de algum processo avaliativo do trabalho feito, $67,0 \%$ dos serviços responderam afirmativamente. Esses valores foram de $84 \%$ no Rio, 77,8\% em Curitiba, 75\% em Brasília, $52,9 \%$ em Recife e 55,6\% em Manaus.

A quase totalidade dos serviços $(98,1 \%)$ das cinco cidades afirma ter perspectiva de continuidade do seu trabalho. Apenas em Manaus, 5,6\% deles responderam negativamente. Esse dado se deve ao término do atendimento pré-hospitalar feito pelo SOS e pelo Corpo de Bombeiros e o de um serviço ambulatorial para vítimas de violência sexual que foi extinto.

A Política Nacional de Prevenção aos Acidentes e Violências é conhecida apenas por $57,7 \%$ dos serviços pesquisados, indicando que a sua divulgação não tem sido realizada satisfatoriamente. Em Brasília e em Curitiba os percentuais sobem para $62,5 \%$ e $61,1 \%$, respectivamente. Não foi possível coletar essa informação para o Rio de Janeiro. Em Manaus 72,2\% dos serviços disseram conhecê-la e em Recife apenas $47,1 \%$. Os pesquisadores observaram, entretanto, que muitas das vezes o informante afirmava conhecê-la apenas pelo embaraço de afirmar o contrário.

O atendimento pré-hospitalar, hospitalar e de reabilitação às vítimas de acidentes e violências segundo a ótica de gestores

$\mathrm{O}$ atendimento pré-hospitalar é aquele prestado aos quadros agudos, clínicos ou traumáticos, no primeiro nível da atenção. A rapidez e eficiência dessa atenção são tão decisivas para a sobrevivência do paciente quanto para evitar seqüelas posteriores. O pré-hospitalar fixo pode ser prestado pelas UBS, PSF, Programas de Agentes Comunitários de Saúde (Pacs), ambulatórios especializados, serviços de diagnóstico e terapia e pelos Serviços de Pronto Atendimento 24 horas (SPA). Estes nem sempre atendem vítimas de acidentes e violências, que são removidas para as grandes emergências hospitalares. Inclui ainda ambulatórios especializados na atenção às vítimas de violências interpessoais, in- 
trafamiliar e outras. O pré-hospitalar móvel é responsável pelo resgate das vítimas e encaminhamento para o atendimento pré-hospitalar fixo ou para o atendimento hospitalar ${ }^{13}$.

Esse nível de atenção foi avaliado pelos gestores como permeado por problemas que afetam diretamente a qualidade da atenção. No que concerne ao pré-hospitalar fixo, os gestores avaliam haver insuficiência de leitos/vagas dada a grande demanda. Em Recife, os SPA das policlínicas possuem uma demanda clínica grande e deixam de realizar o atendimento às pequenas lesões, por insuficiência de profissional e por indefinição dessa política, sobrecarregando as emergências.

A atenção do pré-hospitalar móvel em algumas cidades encontra-se cindida entre duas instituições: o Corpo de Bombeiros e o Serviço de Atendimento Médico de Urgência (Samu), lançado pelo Ministério da Saúde em 2003. Em Manaus, em 2005, marcava-se a transição do atendimento do Corpo de Bombeiros e o SOS resgate, de responsabilidade da prefeitura, para o Samu. Os gestores avaliam que essa cisão é motivo de polêmicas e desentendimentos ( situação não relatada em Curitiba). Os gestores ligados ao Corpo de Bombeiros argumentam que esta instituição possui mais experiência acumulada (atua há mais de 25 anos) e equipes capacitadas. Em contrapartida, não tem sido beneficiada por recursos, sofrendo um processo de sucateamento. A passagem ou readequação das atribuições entre ambas as instituições tem gerado descontinuidades e pouca troca de informações entre as duas equipes.

No que concerne à realização do trabalho de resgate, os entrevistados de Recife, Brasília e Rio analisam as constantes dificuldades para conseguir vagas nos hospitais. Situações inusitadas são relatadas no Rio, como a de pacientes com quadros graves que sequer são recebidos nas emergências diante da alegação de falta de especialistas, demandando da equipe de resgate uma peregrinação na busca de atendimento. Como alternativa, os profissionais lançam mão da rede pessoal de conhecimentos para que o paciente seja "aceito" no serviço.

Outros depoimentos revelam que embora os serviços de resgate devam consultar os de emergência sobre a disponibilidade de vaga, evitando deslocamentos desnecessários, na prática, essas equipes decidem não avisar, temendo receberem negativas a priori. Optam por chegar com o paciente e só então tentar negociar sua entrada. Em Manaus foram assinalados sérios problemas de resgate de vítimas que moram no interior, havendo pacientes que morrem devido à demora na remoção.

A falta e/ou a lenta rotatividade de leitos e a in- suficiência de recursos e pessoal, associadas ao alto contingente de atendimentos, parecem dar os contornos da resistência para aceitar pacientes mais graves, relatada por alguns entrevistados. Um gestor de Recife relata: "muitas vezes temos que deixar a maca com o paciente por falta de leito". Um gestor do Rio menciona que o profissional do pré-hospitalar é visto "como alguém que vem trazer problemas". Esses obstáculos e conflitos podem significar seqüelas consideráveis e até a morte dos usuários.

Em algumas cidades é relatada a desarticulação do pré-hospitalar com o atendimento de emergência. Isso colide seriamente com as orientações do Ministério de Saúde, de que haja na retaguarda uma rede de referência de serviços de outros níveis de complexidade, mediados pela Central de Regulação, com fluxos definidos e mecanismos de transferência de pacientes ${ }^{13}$.

O atendimento de emergência é o que revela maior complexidade gerencial e, como corrobora a literatura, sofre os problemas crônicos da superlotação, invasão de demanda ambulatorial e de municípios vizinhos menos aparelhados, e da falta de leitos de retaguarda ${ }^{14,15}$.

A esse quadro soma-se a falta de articulação intra-hospitalar, sendo difícil o setor de emergência ter acesso a leitos nas enfermarias, exames complementares, avaliação por especialistas e encaminhamentos para setores internos ao hospital, o que ocasiona inevitável congestionamento. Da mesma forma se verifica que alguns hospitais de referência não possuem equipes completas, ora faltando neurocirurgiões, ortopedistas, ora outros especialistas. Em Manaus, por exemplo, apenas um hospital possui neurocirurgião e um outro dispõe do único atendimento em emergência oftalmológica desta cidade. Segundo gestores, no Rio, toda a Zona Oeste sofre de falta de neurocirurgiões.

Essas situações ferem o que preconiza o Sistema Estadual de Referência Hospitalar em Atendimento de Urgência e Emergência, pactuado entre Ministério da Saúde, Estados e municípios. O referido sistema define a implantação de redes regionalizadas e hierarquizadas de atendimento, que permitiria melhor articular serviços, definir fluxos e referências resolutivas, elementos indispensáveis para a universalidade de acesso e qualidade do atendimento ${ }^{13}$.

Gestores do Rio indicam descontinuidade de insumos e materiais, não raro faltando medicamentos básicos. Refletem ainda que o setor de emergência sofre de considerável rotatividade de profissionais, muitas das vezes permanecendo os médicos que não têm o perfil de emergencistas. 
Mencionou-se que as equipes do fim de semana (momento crítico para os atendimentos de acidentes e violências) são as mais despreparadas, com profissionais jovens e estagiários. Comumente, nos horários da madrugada, eles se vêem sozinhos, com orientação para chamar o médico plantonista se houver necessidade.

Segundo as entrevistas, o setor de reabilitação é, em todas as cidades, o mais precário dentre as frentes de atendimento às vítimas de acidentes e violência. Os gestores revelam o claro sentido de desvalorização que este setor recebe na agenda dos municípios. O primeiro diagnóstico que fazem é o da insuficiência de leitos para estes atendimentos, além da existência de poucos serviços nas cidades para uma demanda reprimida e crescente. Logo, a espera pelo atendimento é grande. Dessa forma, os serviços se vêem diante da terrível escolha entre realizar um atendimento mais prolongado, conforme cada demanda, ou diminuir o tempo de acompanhamento para aumentar a cobertura.

Os gestores consideram ainda que os serviços disponíveis estão mal distribuídos geograficamente. Tal fato evidencia o pouco planejamento do setor no que concerne ao quadro de morbimortalidade das cidades. As condições de atendimento também merecem a avaliação crítica. Os serviços nem sempre contam com equipes multidisciplinares. A precária manutenção dos equipamentos e a falta até daqueles mais baratos (bolas, por exemplo) são mencionadas, bem como a falta de órteses e próteses.

A pouca ou inexistente articulação intersetorial e mesmo setorial é motivo de profunda crítica dos gestores. As unidades de emergência não orientam os pacientes sobre a necessidade da reabilitação. Conforme os gestores, os profissionais de saúde "parecem não compreender" a importância de um encaminhamento rápido para que muitas seqüelas sejam evitadas. Outros relatos consideram isso uma "falta de compromisso" com a posterior qualidade de vida do paciente. Nesse sentido, destaca-se a iniciativa de um serviço de Manaus (Programa de Atividades Motoras para Deficientes - Pro-Amde, da Universidade Federal do Amazonas), que faz uma ação de beira de leito nas emergências. Contudo, possuem apenas 40 vagas para realizar esse acompanhamento para uma demanda que se estima bem superior.

A avaliação dos gestores é de que a área da Saúde pouco interage com setores essenciais para a qualidade de vida e inserção social das pessoas seqüeladas. Os setores de transporte, educação, desenvolvimento social e trabalho são os mais citados como fundamentais para uma ação mais integral.

A forma do registro na área de reabilitação, como também foi observado no setor de emergência, impossibilita um monitoramento do impacto dos acidentes e violências na demanda por reabilitação. Quando o diagnóstico é "trauma", não há referência sobre a causa que levou à incapacidade, informa-se apenas a Classificação Internacional de Doenças (CID) da lesão, portanto não há como saber quantos pacientes foram atendidos ou quantas órteses e próteses foram disponibilizadas em conseqüência de traumas por acidentes de trânsito e/ou violências.

Segundo os depoimentos, a atenção dispensada à reabilitação não cumpre satisfatoriamente as diretrizes da Política Nacional de Redução de Morbimortalidade por Acidentes e Violências nos principais aspectos relativos ao atendimento em reabilitação: integração do paciente e sua família no atendimento; oferta de atendimento multiprofissional, buscando evitar seqüelas e incapacidades, além de proporcionar condições para sua reinserção na família, trabalho e sociedade de forma geral; oferta de recursos de reabilitação; orientação e apoio que favoreçam ao paciente e sua família; sensibilização e informação aos gestores e profissionais de saúde sobre os papéis na orientação dos portadores de seqüelas e familiares ${ }^{12}$.

As situações relatadas pelos entrevistados também estariam em desacordo com o que postula a portaria 818 do Ministério da Saúde, que cria mecanismos para a organização e implantação de Redes Estaduais de Assistência à Pessoa Portadora de Deficiência Física ${ }^{16}$. Entretanto, a realidade aqui observada parece ser comum nas demais capitais do país. Segundo diagnóstico da Política Nacional de Saúde da Pessoa Portadora de Deficiência, a situação dessa assistência no país é precária, de baixa cobertura, centralizada na região Sudeste, de pouca sensibilização dos gestores em relação à questão. Eainda a insuficiente remuneração do leito de reabilitação, e a incipiente articulação com os hospitais universitários para a atenção especializada. Verifica ainda a descontinuidade da oferta de órteses, próteses e bolsas coletoras ${ }^{16}$.

\section{Conclusões}

A caracterização diagnóstica inicial aponta importantes aspectos para o debate sobre atenção às vítimas em capitais onde os índices de acidentes e violências são notoriamente altos. $\mathrm{O}$ atendimento aos idosos ainda pouco se destaca. Contrariando o que sugerem várias experiências internacionais no atendimento às violências domésticas, a família tampouco é tomada como um grupo de atenção. 
As ações de prevenção não fazem parte do cotidiano da totalidade dos serviços, o que se esperaria de instituições cujo atendimento às vítimas é rotineiro. Essa situação é crítica em Manaus e Curitiba.

O suporte social, o atendimento nos níveis ambulatorial e hospitalar são as ações mais empreendidas. $\mathrm{O}$ atendimento psicológico também constitui oferta para quase metade dos serviços, havendo defasagem no Rio e Curitiba. Os grupos de pais e a visita domiciliar, estratégias importantes no atendimento às situações de maustratos contra crianças e adolescentes, ainda são pouco empregadas.

O significativo percentual de encaminhamentos oriundos das UBS indica positivamente a identificação de situações que requerem atenção no seio das comunidades e famílias. Contudo, as parcerias precisam ser constantemente fortalecidas e expandidas as referências setoriais e intersetoriais.

A capacitação dos profissionais para o atendimento às vítimas de acidentes e violências mostra a necessidade de maior continuidade e investimento, especialmente em Recife.

$\mathrm{O}$ registro dos atendimentos, elemento essencial para o planejamento de ações mais efetivas e para a prevenção, ainda se revela precário, a maioria feita manualmente.

Num contexto em que a própria Política Nacional de Redução de Morbimortalidade por Acidentes e Violências é pouco conhecida, observase a desarticulação inter e intra-institucional, entre os setores de atendimento pré-hospitalar e de emergência. Esse cenário, que vem melhorando nas cidades de Recife e Curitiba, ainda é crítico no Rio e em Manaus. Os conflitos entre os serviços de resgate, Samu e Corpo de Bombeiros indicam a necessidade de uma parceria e redefinição urgente dos papéis. O setor de emergência também se mostra pouco articulado com o setor hospitalar em algumas ocasiões. Constata-se, em todas as cidades, a insuficiência da oferta dos serviços de reabilitação.

Numa tentativa de esboçar um indicativo diagnóstico da situação dos serviços nas diferentes cidades, tomou-se um conjunto de nove questões consideradas importantes pela Política Nacional de Redução de Morbimortalidade por Acidentes e Violências. São elas: 1) atendimento a todas as faixas etárias; 2) realização de ações de prevenção; 3 ) oferta de atendimento ambulatorial e hospitalar; 4) registro informatizado; 5) composição de equipe multidisciplinar mínima (médico, assistente social e psicólogo); 6) capacitação regular aos profissionais; 7) articulação setorial - recebimento de pacientes de Unidades básicas de saúde e Programa Médico de Família. As questões 8 e 9 analisam a articulação intersetorial da Saúde, elegendos dois setores importantes no atendimento às vítimas de acidentes e violências: o de Defesa de Direitos e a área de Segurança Pública. O item 8 analisa se os serviços realizam encaminhamentos para o CT e o 9 verifica se os serviços recebem encaminhamentos das DPCA e DEAM. Operouse com um marco de corte de 50\%. Assim, a cidade que igualou ou ultrapassou essa marca recebeu um ponto. Fazendo-se a ressalva da incomparabilidade entre cidades e da disparidade entre número de serviços de cada cidade, tem-se que o Rio de Janeiro apresentou maior pontuação. Brasília, Curitiba e Manaus revelam posições intermediárias. Recife teve menor pontuação, mas em contrapartida apresenta um maior número de unidades de atendimento. Vale ressalvar que, mesmo essas cidades com melhores percentuais, possuem ainda consideráveis lacunas, demandando investimento contínuo para a oferta de uma atenção de qualidade às vítimas.

\section{Colaboradores}

SF Deslandes, ER Souza, MCS Minayo, CRBSF Costa, M Krempel, Ml Cavalcanti, MLC Lima, SJ Moysés, ML Leal e CN Carmo participaram igualmente na elaboração deste artigo. 


\section{Referências}

1. Brasil. Ministério da Saúde. Datasus. Informações de Saúde, 2006 jan. [acessado 20 mar 2006]. Disponível em: www.datasus.gov.br.

2. Brasil. Ministério da Saúde. Política Nacional de Redução de Morbimortalidade por Acidentes e Violências. Brasília, MS; 2001.

3. Minayo MCS. Introdução: o conceito de avaliação por triangulação de métodos. In: Minayo MCS, Assis SG, Souza ER, organizadoras. Avaliação por triangulação de métodos. Abordagem de programas sociais. Rio de Janeiro: Ed. Fiocruz; 2005. p. 19-51.

4. Denzin NK. The research act. Chicago: Aldine Publishing Company; 1973.

5. Deslandes SF, Assis SG. Abordagens quantitativas e qualitativas em saúde: o diálogo das diferenças. In: Minayo MCS, Deslandes SF, organizadoras. Caminhos do pensamento: epistemologia e método. Rio de Janeiro: Ed. Fiocruz; 2003. p. $195-226$.

6. Minayo MCS, Assis SG, Souza ER, organizadoras. Avaliação por triangulação de métodos. Abordagem de programas sociais. Rio de Janeiro: Ed. Fiocruz ; 2005.

7. Brasil. Ministério do Planejamento, Orçamento e Gestão. Instituto Brasileiro de Geografia e Estatística. Mar 2006 [acessado 13 mar 2006]. Disponível em: www.ibge.gov.br.

8. Souza ER. Ranking de mortalidade por homicídio, suicídio e acidente de transporte em municípios com mais de 100.000 habitantes. Rio de Janeiro: Claves/ENSP/Fiocruz; 2004. [Mimeo].
9. Bardin L. Análise de conteúdo. Lisboa: Edições 70; 1979.

10. Minayo MCS. O desafio do conhecimento. São Paulo: Hucitec; 2004.

11. Assis SG E, Constantino P. Violência contra crianças e adolescentes: o grande investimento da comunidade acadêmica na década de 90. In: Minayo MCS, Souza ER, organizadoras. Violência sob o olhar da saúde. Rio de Janeiro: Ed. Fiocruz; 2004.

12. Deslandes SF, Assis SG, Njaine K, Ximenes LF, Gomes R, Cabral CA, et al. Famílias: parceiras ou usuárias eventuais? Análise de serviços de atenção a famílias com dinâmica de violência doméstica contra crianças e adolescentes. Brasília: Claves/ENSP/Fiocruz, Unicef; 2003.

13. Brasil. Ministério da Saúde. Política Nacional de Atenção às Urgências. Brasília: MS; 2003.

14. Deslandes SF. Frágeis deuses. Profissionais de emergência: entre danos da violência e a recriação da vida. Rio de Janeiro: Ed. Fiocruz; 2002.

15. Giglio-Jacquemot A. Urgências e emergências em saúde: perspectivas de profissionais e usuários. Rio de Janeiro: Ed. Fiocruz; 2005.

16. Brasil. Ministério da Saúde. Manual de Legislação em Saúde da Pessoa Portadora de Deficiência. Brasília: MS; 2003.

Artigo apresentado em 20/03/2006

Aprovado em 30/03/2006

Versão final apresentada em 4/04/2006 